\title{
The Application of Digital Technology in the Protection of Intangible Cultural Heritage - Taking Beijing Palace Carpets as an Example
}

\author{
Baitao Jiang ${ }^{1, *}$ \\ ${ }^{1}$ Beijing Information Technology College, Beijing, China \\ *Corresponding author. Email: jiangbt@bitc.edu.cn
}

\begin{abstract}
The patterns, decorations and exquisite skills of Beijing palace carpets show the meaningful national culture that is passed down through body language and oral instruction. They are not only a concrete display of ancient people's world view, outlook on life, and values, but also convey image language and textual information related to natural science and cultural knowledge. As one of the typical intangible cultural heritage, the protection and inheritance of Beijing palace carpets must be based on the principle of "taking the protection as the principal thing, rescuing firstly, using rationally, and inheriting and developing", so as to record, research and inherit the representative skills, original hand-drawn draft maps, textures and materials and even the body language of the inheritors of Beijing palace carpets in a comprehensive and brand-new way; at the same time, at the moment when digital technology is involved in social development, Beijing palace carpets, as an integral part of cultural inheritance and development, should also explore ways and methods to achieve innovative transformation and creative development.
\end{abstract}

Keywords: Beijing palace carpet, Intangible cultural heritage, Digital technology.

\section{INTRODUCTION}

As a representative of traditional palace art, Beijing palace carpet was listed as an intangible cultural heritage in 2008. Its skills are stunning and exquisite beyond compare. However, because its weaving completely relies on handwork, the materials are unique and expensive, and its shape, pattern, color and other aesthetic tastes are very different from today's social life, it is difficult for it to enter ordinary people's daily life as daily use or ornaments. As a result, it faces a series of problems such as poor circulation of most products and reduction of inheritance scale, and only becomes a research object for museums, private collections and professionals. Fortunately, today, with the development of technology, through the digital application represented by virtual reality, the technology that was originally passed down mainly by oral instruction through family lineage or master-apprentice relationship, and appreciated by touch and play, has become involved in contemporary society in another way, facilitating the public's access to the treasure of intangible cultural heritage at zero distance in addition to specialized research.

\section{DIGITAL ACQUISITION AND STORAGE}

Some intangible cultural heritage projects need to convey the complicated and ingenious "workmanship culture". Therefore, it is obviously not enough to only seek the tangible display of finished products. [1] A process-oriented dynamic display is also needed, that is, the live display of intangible cultural heritage. The collection of video materials and VR (virtual reality) action materials has established a relatively complete record for the teaching and practical application of the intangible cultural heritage master's skills, as well as the operation process of the palace carpet weaving skills, playing an important role in preserving the original creation process and constructing a digital archive platform. At the same time, relying on digital acquisition and storage, the Beijing palace 
carpet can be applied to different display scenes and environment.

\subsection{The Application of Flat Scanning Technology}

For some original manuscripts of the Beijing palace carpets, after decades or even hundreds of years, some of them have been gradually damaged due to inadequate preservation. As one of the important and representative projects of intangible cultural heritage, the preservation of the original manuscripts of the Beijing palace carpet is a matter of urgency. With the help of digital technology, the original precious pattern manuscripts of the Beijing palace carpet can be scanned with a large-format scanner to preserve original manuscripts. The original exquisite manuscripts of those masters also rely on collection techniques to retain the "soul" and "form" they have inherited. In addition to the manuscripts, it is also important to scan the original cultural relics of the existing Beijing palace carpets. However, it should be noted that the decision will be based on the form of the scanned carpet to decide whether to use the flat scanning or the $3 \mathrm{D}$ acquisition technology mentioned later. For example, because of the emphasis on decoration and appreciation, the Panjin carpet (盘金毯子, a kind of carpet inlaid with gold threads on the front and silk threads on the back) adopts embossed craftsmanship, which requires 3D scanning data collection.

The flat scanning technology of Beijing palace carpet mainly relies on flatbed scanners, roller scanners, fold-line optical path scanners, multi-lens scanners, etc. to be achieved. Flatbed scanners are more suitable for large-scale scanning of palace carpets, and they are excellent and efficient in several indicators such as picture width, scanning speed and definition. Roller scanners have a deeper application effect and they are also the main equipment for scanning the manuscripts of Beijing palace carpets, mainly including Colortrac (卡莱泰克 ), Contex (康泰克斯), and Graphtec (日图). From the point of view of practical application, if comprehensively considered, the Colortrac scanner is the best in terms of equipment use, imaging technology and ease of use of the software, especially its scanning software is very convenient to use. It can be processed online later and can perfectly display the detailed color images in the original manuscripts of the Beijing palace carpet. Usually when scanning the Beijing palace carpet, the manuscript within 1.3 meters doesn't need to divide the large file into several parts and scan separately for image stitching. The image capture color is 48-bit true color, using the full-size professional camera lens and advanced image data processing algorithm, which can maximize the excellent image quality of scanned manuscripts. The original manuscript of the Beijing palace carpet is generally about 2 meters in length and width. The maximum width of the large-format high-definition scanner can reach 54 inches or $1.37 \mathrm{M}$, the scanning speed is 12 inches/sec, and the definition is about 9000dpi. Manuscripts that exceed the scan width require software stitching and data storage.

\subsection{The Application of 3D Acquisition Technology}

The 3D acquisition technology mainly depends on a $3 \mathrm{D}$ scanner to achieve. Its working principle is to transmit detection signals through equipment to detect and analyze the shape (geometric structure) and appearance data (such as color, surface albedo, etc.) of objects or environment in the real world. Then, it uses the collected data to perform 3D reconstruction calculations, and creates a digital model of the actual object in the virtual world. In specific application, the precious original morphological features of Beijing palace carpet can be restored by scanning with a 3D scanner. The generated digital 3D palace carpet data can perfectly restore the clip planes, the height of the wool, and the slope effect of the palace carpet. The 3D scanning methods include contact scanning and non-contact scanning. Non-contact scanning has an absolutely important protection value for the original cultural relics of Beijing palace carpets. The contact scanning must touch the object during the scanning process and the scanned object may be damaged by the probe, so it is not suitable for scanning the high-value Beijing palace carpet cultural relics. But its advantage lies in calculating the depth by actually touching the surface of the object, and then obtaining quite accurate data, which is mostly used in the replication and research of modern products. In addition, compared with other methods, contact scanning takes a longer time. Non-contact 3D active scanning refers to projecting additional energy to an object, and calculating 3D spatial information through energy reflection. Common projected energy includes general visible light, high-energy beam, ultrasound or X-ray, etc. The main brands are German DAVID, American NextEngine (an American desktop 3D scanner company), and Chinese Microtek ScanMaker and so on. Through 3D 
scanning, it can be stored in various standard 3D formats (OBJ, STL, PLY, etc.), which is convenient for the detailed research, product display, craft production, virtual operation and so on.

\subsection{The Motion Capture of Representative Inheritance Skills}

The inheritance of intangible cultural heritage represented by the Beijing palace carpets has the characteristic of oral instruction, but because some of the representative inheritors have long been rooted in the skills themselves, they have not received a high level of education. In the process of inheritance, it is inevitable that some skills, especially the skills and motions that are inadvertently revealed, cannot be well taught to later generations in language, let alone the writing of a book of one's own skills and experience. With the development of digital technology, image collection has become an important part of the protection and inheritance of intangible cultural heritage, but it is also difficult for simple image collection to fully express all the minor details of habitual actions of the inheritors. Therefore, the use of advanced optical motion compensation equipment to capture the motions of the inheritors of the Beijing palace carpet has become an important direction for the application of digital technology in intangible cultural heritage. From the current application situation, the better ones in optical capture are Motion Analysis (an American optical instrument system manufacturer), Nokov (a Chinese motion capture system manufacturer), Vicon (a British motion capture system manufacturer), and Optitrack (a full-body motion capture system provider) and so on. Among them, the Chinese motion capture system manufacturer Nokov is accurate and easy to use, which is more suitable for the motion capture of the Beijing palace carpet inheritors. Its collector is close to everyday clothes, light and comfortable to wear without complicated circuits, and it captures the details of the inheritor's motions with precision. The process of Beijing palace carpet is complicated. Each step of the technical motions such as slitting, spinning, twisting, underpainting, through the weft, off the machine, flattening and trimming, etc. can be meticulously recorded by the Nokov (Nokov motion compensation system). In particular, it can add positioning points to the hands, and capture the extremely fine technical motions and even the force skills. It uses computer collectors to summarize and organize to generate $3 \mathrm{D}$ motion data files, and to attach model bones through $3 \mathrm{D}$ software such as 3ds max and MAYA. It uses UE4 or U3D technology to further display and experience the exquisite and complete manufacturing skills of the Beijing palace carpet inheritors in the virtual reality space with direct screen, ring screen, arc screen, helmet and VR glasses, CAVE projection system and other equipment. Compared with traditional paper and image cognition, it is more intuitive, interactive and interesting. Its data storage is also more reliable, and the transmission form is flexible and diverse, which can be used as a display for ordinary audiences or as a teaching resource for learning.

\section{THE DIGITAL EXPERIENCE OF BEIJING PALACE CARPETS}

Judging from the current existence and operating conditions, Beijing palace carpets are small in scale and low in output. The reason is not the quality of the product, but the lack of a way for the public to recognize the Beijing palace carpet. Today, the application of digital technology can enable intangible cultural heritage projects represented by Beijing palace carpets to be promoted to the public in diversified forms. One can set up experience areas in museums or share resources on the Internet, so that the public can really enjoy the benefits of digitalization and make the intangible cultural heritage alive. Digital experience breaks the geographical and physical space constraints of intangible cultural heritage projects, and transforms from "material-oriented" to "information-oriented" and from "information acquisition" to "interactive experience" through virtual technology. [2] For example, the Beijing palace carpet can use digital technology to integrate VR, digital perception, human-computer interaction and other elements so that the audience can hear, see and even touch personally, and understand the production process, craftsmanship, history and other information of the palace carpet. The audience can also use digital technology to go back to the palace hundreds of years ago to experience the use, appreciation, and play experience of the ancients.

\subsection{CAVE Immersive Experience}

The Beijing palace carpet virtual reality display built with CAVE is a highly immersive virtual presentation environment consisting of three or more (including three) rigid rear projection walls, with a 3D tracker allowing close access to the virtual Beijing palace carpet made up of digital 
signals in a system surrounded by projection walls. CAVE is a new, advanced, and completely immersive data visualization method, which can be applied to any virtual simulation application field with immersive requirements. Through the CAVE immersive experience, the audience can walk around in a 3D virtual space and see the Beijing palace carpets displayed in the palace. They can also touch the Beijing palace carpets through gloves and handle devices. They can even try the weaving process from the first point of view, and learn weaving skills and so on.

\subsection{Digital Gaming Experience}

VR technology is the integrated use of graphical data programs and various control interface hardware devices to generate a Beijing palace carpet weaving game experience model on a computer. For the digital game experience, it needs to be realized through $\mathrm{U} 3 \mathrm{D}$, UE4 and other software to integrate the palace carpet weaving skilled motions. This part involves a lot of specific work. For example, it's needed to integrate representative technical motions, and each motion requires a complete set of animation. In addition, more technical demonstrators should be carried out to adapt skeletal characters, a motion humanoid (humanoid skeleton) format should be processed for the entire technical operation process, and FBX files should be exported by Max after the motion display is completed. At the same time, some settings should be made and the humanoid (humanoid skeleton) solution in Max should be adapted. Here the representative inheritor can be chosen as a character motion to make a set of skeletal animation, and other character motions can share with him. In the process of weaving palace carpets, one needs to stand or sit down. The most obvious difference between the two is the different posture of the lower part of the body, which is also technically required. For example, when making standing weaving and other motions, assuming that the upper body motions are basically the same, the status of sitting down should be considered. Taking a standing motion as an example, to do a fusion of sitting and weaving, one needs to do a sitting and weaving motion so that it merges with the standing motion. The upper body remains unchanged and the lower part of the body adopts a sitting motion, adopting a mixed motion operation method, later using blend type to perform motion fusion, and using parameter and threshold values to perform different motion fusion operations. Through the production of a motion program of a representative skill demonstrator, one can experience the weaving role control from the first perspective on the mobile phone like a game, and experience each palace carpet's production process and a series of corresponding tasks. The powerful experience advantage of the first perspective will also bring revolutionary changes to the entire inheritance of intangible cultural heritage. They will be favored and loved by the younger generation, making the Beijing palace carpet an important step in the inheritance and development of intangible cultural heritage projects.

\section{THE DIGITAL PROMOTION OF BEIJING PALACE CARPETS}

Modern society is the era of information. The way people obtain information and knowledge has changed from active to passive. People's needs have shifted from acquiring "rich information" to acquiring "more effective information", which is caused by changes in lifestyles and attitudes and ideas. Based on the fast-paced and high-pressure situation of modern life, how to effectively transmit information of traditional culture, and how to optimize the recognition of Beijing palace carpets to the depths of people's hearts, will re-establish the emotional expression and emotional release of the Beijing palace carpets as the representative of the intangible cultural heritage in people's life.

\subsection{The Form of Documentary}

Today, information floods people's life in many ways. People have to passively accept a variety of information, which leads to many people not actively paying attention to information related to intangible cultural heritage. However, good film and television works have become an important channel for people to understand intangible cultural heritage, for example, documentaries such as "A Bite of China", "National Treasures", and "Masters in Forbidden City" have become a way for the public to understand traditional culture, quickly received heated extolling of the whole people, and ignited people's thinking about traditional culture and art so that they have new thinking about traditional life. The China Beijing TV Station has aired documentaries such as "The Eight Wonders of Yanjing - Palace Carpets" and "Saving the Lost Art of the Palace Carpets". These documentaries sort out the historical origin and development of Beijing palace carpets, which have a good social impact. However, with the development of media formats in recent years, the traditional form of 
documentary is too serious and the channels for dissemination are limited.

\subsection{The Digital Promotion of Mobile Terminals}

In the future, the development of $5 \mathrm{G}$ communication technology and the digital promotion of mobile intelligent terminals will play a key role in the dissemination and promotion of intangible cultural heritage. [3] From the current aspects of We-Media dissemination content, dissemination carrier and dissemination form, the development of We-Media makes everyone become the subject, and everyone is both a producer and a disseminator, which greatly strengthens the ability of information dissemination. The Beijing palace carpet is actually not a widely known type of intangible cultural heritage project. Compared with the popular forms such as Kun Opera and acrobatics, the understanding of palace carpets may still remain in a fragmented stage, presenting a relatively vague impression. And mobile terminals can connect these fragmented products in series through short videos, and adapt to people's reading and dissemination needs. In order to better adapt to this fragmented cognitive feature, in the process of digital promotion of the mobile terminal of Beijing palace carpet, more attention should be paid to exploring new media forms of short videos to attract people's attention, impact people's visual perception, and cause the resonance of the fragmented knowledge in the memory after serialization. In fact, how to use fragmented information to convey the culture of intangible cultural heritage is also a new topic in the digital age. Through short videos and the cultural push of contemporary Internet celebrity products, the cultural heritage represented by museums is displayed in a form that people are willing to accept.

\subsection{Digital Museums}

In order to better inherit the Beijing palace carpets, the construction of the Beijing Palace Carpet Digital Museum has been completed, which uses VR technology to realize interactive and dynamic virtual reality demonstrations, vividly displaying the colorful intangible cultural heritage resources of Beijing palace carpets, enabling the audience to experience the charm of intangible culture personally. The overall design of the intangible cultural heritage digital museum perfectly integrates fashion elements with the old
Beijing architecture. There are two virtual exhibition halls, the main intangible cultural heritage VR experience hall and the VR exhibition hall, to display the intangible cultural heritage achievements of Beijing palace carpets in different categories. The exhibition halls of the experience hall are connected to each other and users can enter other exhibition halls through the connection guidance in the exhibition hall, and select the column through the scene at the bottom left. The whole museum uses CGI (Computer-Generated Imagery) and $360^{\circ}$ panoramic VR technology to produce, and through texts, photos, phonotape and videotape, videos, CG animations and models, etc., it introduces in detail the historical origin, inheritance area, display form and cultural value of the Beijing palace carpet intangible heritage project, fully displaying the important measures and achievements of Beijing palace carpets in the practice of intangible cultural heritage protection, inheritance and development. The project display can be realized through PC, mobile, and VR glasses equipment. Users can enter VR mode through the VR button function on the mobile phone. After placing the mobile phone horizontally into the VR device, users can put on the helmet to feel the effect of being in it.

\subsection{Digital Sharing Platforms}

Through the use of APP to establish a sharing learning platform for Beijing palace carpets, the culture of intangible cultural heritage enters the public, which enhances its economic value, injects development vitality, and promotes the development of cultural resources and industry. [4] The Beijing palace carpet should not only become the research results of a few experts and stand high above the masses, nor should it work behind closed doors and be conservative, but should be actively integrated with people's daily life, integrating with the spirit of the times, so that people can love their national culture more in contact with traditional culture. It is necessary to establish the dissemination and ideological identity of intangible cultural heritage through the sharing and service of intangible cultural heritage. Through the development of digital distance education and training, it is possible to promote the dissemination of the culture of intangible cultural heritage, develop skills and services, and gradually change the history of Beijing palace carpets based on "objects" and form an experience based on "people". 


\section{CONCLUSION}

Today, the digital technology that people are studying is not only to solve the inheritance of a certain skill, but to point to the development trend of the entire hand-crafted culture represented by this. [5] According to different technical skills, with the help of digital means, traditional skills can emit the brilliance of combining science and technology with human civilization. Through the digital research and digital application of palace carpet techniques, a comprehensive system of digital archives, digital experience, digital promotion, and intangible cultural heritage sharing and services can be established, allowing intangible cultural heritage to regain its brilliance under new historical conditions. Digital technology effectively intervenes in current society and life, which can be integrated into the continuation of civilization in a more flexible way, can eliminate the strangeness and mystery of modern people towards intangible cultural heritage, and can also promote the public's consciousness of intangible cultural heritage protection. Just as Mr. Feng Jicai said, "It interacts as both cause and effect for young people to love our own culture - Because of love, we protect. Because of protection, we love". [6]

\section{AUTHORS' CONTRIBUTIONS}

This paper is independently completed by Baitao Jiang.

\section{REFERENCES}

[1] Shan Jixiang. The Protection and Inheritance of Folklore Cultural Heritage and the Construction of Folk Museum [J]. Folklore Studies, 2013(4): 80-88. (in Chinese)

[2] Ma Yi. Protection and Utilization of Intangible Cultural Heritage in the Digital Background [J]. Popular Literature and Art, 2019(24): 3-4. (in Chinese)

[3] Zhou Rui, Qi Guijie. The Construction and Promotion of the Digital Folklore Museum [J]. Folklore Studies, 2013(4): 89-93. (in Chinese)

[4] Tian Xiaoxuan, Ma Xiuwei. Digital Exploration in the Inheritance of Intangible Cultural Heritage [J]. Culture Journal, 2019(1): 156-158. (in Chinese)

[5] Lv Ming, San Shuo, Sun Guohang. The Significance and Application of Digital Inheritance and Protection of Intangible
Cultural Heritage [EB/OL]. (2018-0928)[2021-03-25]. https://www.fx361 .com/page/2018/0928/4299330.shtml (in Chinese)

[6] Feng Jicai. The Years Are Silent, Only the Stone Can Speak [J]. Leaders in All Fields, 2018 https://baijiahao.baidu.com/s?id=1612727896 $334999632 \& w f r=$ spider \&for=pc. (in Chinese) 